\title{
A CONTEXTUALIZAÇÃO DO CURRÍCULO FRENTE ÀS NOVIDADES CIENTÍFICAS NA FORMAÇÃO INICIAL EM CIÊNCIAS BIOLÓGICAS E PEDAGOGIA
}

\author{
THE CURRICULUM CONTEXTUALIZATION IN THE FACE OF \\ SCIENTIFIC NEWS IN THE INITIAL FORMATION IN BIOLOGICAL \\ SCIENCES AND PEDAGOGY
}

\author{
Adriana Fratoni dos Santos ${ }^{1}$ \\ Lucken Bueno Lucas ${ }^{2}$ \\ Marinez Meneghello Passos ${ }^{3}$ \\ Sergio de Mello Arruda ${ }^{4}$
}

\begin{abstract}
Resumo: O artigo apresenta os resultados de uma pesquisa que investigou, junto a um grupo de licenciados de Ciências Biológicas e de Pedagogia, a forma como o currículo escolar tem sido abordado em sua formação inicial. A partir de um curso formativo, o currículo escolar relacionado ao ensino de Ciências Naturais foi discutido com esses estudantes quanto à sua abertura para os conhecimentos recentes de suas áreas de referência. Os dados coletados abrangeram respostas a um questionário, analisados com base nos pressupostos da Análise Textual Discursiva. Do processo analítico, foi evidenciado uma categoria denominada "Formação docente" que revelou, em três subcategorias, as percepções dos cursistas quanto à insuficiência do debate sobre os saberes curriculares na formação inicial, a compreensão do papel dos professores na contextualização do currículo e a relevância dos conteúdos escolares na aprendizagem dos fenômenos naturais, frente à necessária abertura dos programas curriculares para as novidades científicas.
\end{abstract}

Palavras-chave: Ensino; Currículo e contexto; Formação inicial de professores.

\begin{abstract}
The article presents the results of a research that investigated how curricular knowledge has been approached in the initial formation of a group of students of Biological Sciences and Pedagogy. The school curriculum related to the teaching of Natural Sciences was discussed with these students, in terms of their flexibility and openness to the recent knowledge of their reference areas, in a training course. The collected data included answers to a questionnaire interpreted from the assumptions of the Discursive Textual Analysis. From the analysis, a category called "Teacher education" was evidenced, which revealed,

\footnotetext{
${ }^{1}$ Mestre em Ensino pela Universidade Estadual do Norte do Paraná (UENP), Campus Cornélio Procópio. E-mail: fratonidri@hotmail.com. ORCID: http://orcid.org/0000-0002-6138-1439.

${ }^{2}$ Doutor em Ensino de Ciências e Educação Matemática pela Universidade Estadual de Londrina (UEL). Professor da Universidade Estadual do Norte do Paraná (UENP), Campus Cornélio Procópio. E-mail: luckenlucas@uenp.edu.br. ORCID: http://orcid.org/0000-0003-2122-8672.

${ }^{3}$ Doutora em Educação para a Ciência pela Universidade Estadual Paulista "Júlio de Mesquita Filho" (UNESP). Professora Sênior da Universidade Estadual de Londrina e Professora Colaboradora Sênior da Universidade Estadual do Norte do Paraná (UENP), Campus Cornélio Procópio. E-mail: marinezpassos@uel.br. ORCID: http://orcid.org/0000-0001-8856-5521. Com o apoio do CNPq.

${ }^{4}$ Doutor em Educação pela Universidade de São Paulo (USP). Professor Sênior da Universidade Estadual de Londrina. E-mail: sergioarruda@uel.br. ORCID: http://orcid.org/0000-0002-4149-2182. Com o apoio do CNPq.
} 
DOI: https://doi.org/10.33238/ReBECEM.2021.v.5.n.1.25246

through three subcategories, the perceptions of students regarding the insufficiency of the debate on curricular knowledge in initial education, the understanding of the role of teachers in contextualizing the curriculum and the relevance of school content in the learning of natural phenomena, given the necessary opening of curricular programs to scientific news.

Keywords: Teaching; Curriculum and context; Initial teacher training.

\section{Introdução}

Os programas curriculares apresentam-se à comunidade escolar na forma de documentos oriundos de diferentes instâncias administrativas, como as Secretarias Municipais e Estaduais de Educação, além de órgãos federativos. Em geral, eles elencam conteúdos, perspectivas metodológicas, objetivos de ensino e de aprendizagem e muitos outros aspectos relativos ao universo da formação escolar. A escola, por seu turno, é a instância que organiza e contextualiza esses programas de modo a viabilizá-los como cultura a ser ensinada.

Para melhor compreender o papel desses programas, buscamos subsídios em Tardif (2012), de modo a pensar o currículo a partir do referencial dos saberes docentes. De acordo com o autor, os denominados "saberes curriculares", assim como os da formação profissional e os disciplinares, são obtidos durante a formação inicial de professores, porém apresentam-se "[...] mais ou menos de segunda mão" (p. 40), já que são parte da prática docente, mas não são validados e produzidos por ela, colocando o professor na condição de um aparente executor dos programas curriculares.

Os currículos não são construídos pelos docentes. De fato, eles são feitos e elaborados por instâncias político-educacionais, colocando os professores como agentes principais dos saberes neles expressos, mas que não participam de sua produção e organização.

Assim, pelo fato de os professores não exercerem atuação sobre a organização dos saberes curriculares, ao menos não como uma de suas funções oficiais ordinárias, podem incorrer na consideração dos currículos como elementos estritamente exteriores ao seu domínio, advindos de uma perspectiva impositiva e determinante daquilo que, indiscutivelmente, deverão ensinar.

Com esse entendimento, os saberes curriculares tornam-se elementos distantes dos professores, o que reforça uma convivência extrínseca da prática docente, quando há os que elaboram e os que executam os conhecimentos, colocando os docentes nessa 
DOI: https://doi.org/10.33238/ReBECEM.2021.v.5.n.1.25246

última posição. Nosso entendimento, porém, é de que os saberes curriculares são também campo de atuação dos professores, por isso, precisam ser conhecidos, aprendidos e mobilizados por eles.

Com base nesse movimento reflexivo, da relação dos professores com os saberes curriculares, emergiram durante nossas pesquisas algumas questões relevantes e próprias da realidade cotidiana dos professores, com destaque maior para aqueles que estão iniciando na docência: O que ensinar? Com qual ordenamento sequencial? De que modo apresentar os conteúdos? Como avaliar a aprendizagem deste ou daquele conteúdo? É imperativo seguir fielmente o programa curricular?

Essas e outras questões reportaram-nos para a formação de professores enquanto processo formal, acadêmico e com compromissos muito bem estabelecidos frente ao perfil dos egressos subscritos nos projetos pedagógicos dos cursos de licenciatura, tomando em nosso caso os cursos de Ciências Biológicas e Pedagogia como exemplares de pesquisa, nos quais atuamos como formadores. Nossa inquietação foi resumida na seguinte questão: de que modo um curso formativo, pautado na questão da contextualização do currículo, pode favorecer o processo de formação inicial de professores frente às novidades científicas das Ciências Naturais?

Neste artigo apresentamos parte dos resultados de uma pesquisa de mestrado, desenvolvida em um Programa de Pós-Graduação da Área de Ensino, que investigou os efeitos de uma proposta formativa (no formato de curso) pautada nos saberes curriculares e na inclusão de novos conteúdos ao currículo escolar, com um grupo de estudantes de licenciatura em Ciências Biológicas e Pedagogia de uma Universidade pública do Estado do Paraná.

Exploramos, neste texto, uma parte dos dados relativos às atividades realizadas pelos participantes, relacionada aos saberes curriculares dos professores e à questão dos novos conhecimentos das Ciências Naturais.

Entendemos que esta investigação possa oferecer contribuições para o reconhecimento dos conteúdos recentes das Ciências Naturais como elementos de contextualização dos conteúdos escolares, sugerindo novas compreensões sobre o papel ativo dos professores no que diz respeito à mobilização de seus saberes curriculares.

Assim, após a explicitação da temática central deste artigo, apresentamos em seguida algumas considerações acerca dos saberes curriculares na formação inicial de professores, a possibilidade de diálogo entre os programas curriculares e os novos conhecimentos gerados nas Ciências Naturais, os encaminhamentos metodológicos da 


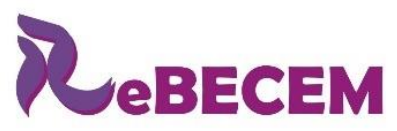

Revista Brasileira de Educação em

Ciências e Educação Matemática

DOI: https://doi.org/10.33238/ReBECEM.2021.v.5.n.1.25246

pesquisa, a apresentação e a análise dos dados e, finalmente, as considerações conclusivas.

\section{Formação inicial e saberes curriculares}

Toda fase de planejamento da prática docente requer, por parte dos professores, domínio dos saberes curriculares. Sobre isso, Gauthier et al. (2013, p. 196) já evidenciaram que, “A função pedagógica de gerenciamento da matéria remete a todos os enunciados relativos ao planejamento, ao ensino e à avaliação de uma aula ou de parte de uma aula", abordando, assim, o conhecimento sobre os conteúdos a serem ensinados pelos professores aos seus alunos, mas levando, também, em consideração, um planejamento sobre os objetivos, conteúdos, estratégias de ensino e todas as alternativas sobre o ambiente educativo. Isso porque, ao tomar decisões pedagógicas sobre os conteúdos a serem ensinados, os professores exercem uma considerável influência sobre a aprendizagem dos alunos.

Vale ressaltar que para Gauthier et al. (2013), os professores podem fazer adaptações nos programas curriculares de modo a atender melhor às necessidades de seus alunos, ou seja, aos professores é flexibilizado organizar de modos diferentes o conteúdo. Mas, os professores, o que pensam sobre isso?

Ao adentrarem na docência, por exemplo, é comum que professores iniciantes empenhem-se em cumprir o currículo em seu formato original, documental e, obviamente, estanque. Nesse sentido, é provável que se tornem fiéis executores de materiais apostilados ou livros didáticos 'perspicazmente' organizados de modo a seguir o ordenamento curricular que, por seu turno, exercerá grande autoridade sobre o planejamento docente.

Segundo Tardif (2012), duas fases podem caracterizar os primeiros anos de carreira docente. A primeira corresponde à “[...] fase de exploração (de um a três anos), na qual o professor escolhe provisoriamente a sua profissão, inicia-se através de tentativas e erros” (p. 84), que pode alternar de difícil ou fácil para cada professor, que inclui as condições que os mesmos encontram em cada instituição educativa, a aceitação pelos alunos e equipe pedagógica, entre outras coisas. Alguns ganham força e experiência para continuar na carreira, outros chegam a desistir da profissão. 
DOI: https://doi.org/10.33238/ReBECEM.2021.v.5.n.1.25246

A segunda é a “[...] fase de estabilização e de consolidação (de três a sete anos), em que o professor investe a longo prazo na sua profissão e os outros membros da instituição reconhecem as suas capacidades" (TARDIF, 2012, p. 85). É o que o autor aponta como um tempo para que um professor tenha desenvolvido maior autonomia em seu trabalho docente, o que vai consolidar maior confiança. Esse tempo de relação entre os saberes dos professores com sua profissão é determinante quando nos referimos à importância do papel dos professores com relação aos saberes curriculares, que estarão na base do trabalho docente.

Dessa forma, os currículos necessitam ser globais, não privados, precisam ser abertos ao diálogo da diversidade, sem diminuir aquilo que já está cultural e cientificamente estruturado (ARROYO, 2013), o que viabiliza o papel dos professores em engrandecer os currículos com os conhecimentos desenvolvidos e apresentados na história recente das Ciências.

Na próxima seção, para subsidiar o que discutiremos nas seções de análises de dados e na de conclusão deste artigo, apresentamos alguns esclarecimentos sobre uma possível relação de flexibilidade e sensibilidade dos programas curriculares frente aos conhecimentos recentes das Ciências Naturais.

\section{Currículo e os novos conhecimentos em Ciências Naturais}

Iniciamos esta seção com um questionamento: seria importante considerar, no âmbito do ensino das Ciências Naturais (seja no Ensino Fundamental, seja no Ensino Médio), os avanços científicos recentes de suas Ciências de referência, a saber: Física, Química e Biologia?

Para oferecer uma resposta a essa pergunta, pautamo-nos nos pressupostos defendidos por Arroyo (2007), de que as Ciências de referência contribuem para entendermos o modo como o conhecimento é produzido e passa a fazer parte da realidade escolar. No entanto, compreendê-las para socializar uma parte desses conhecimentos em forma de conteúdos curriculares, passa a ser uma das responsabilidades dos professores, de modo a significar a Ciência do cotidiano e de que maneira a disciplina escolar específica articula-se com o dia a dia do aluno.

Esse processo advém de uma construção de autonomia, de liberdade pedagógica e de compreensão do processo de formação escolar: 
DOI: https://doi.org/10.33238/ReBECEM.2021.v.5.n.1.25246

\begin{abstract}
As ciências podem ajudar-nos a entender como em cada tempo de vida acontecem a socialização, as capacidades de aprender a cultura e os significados do mundo, da vida, da convivência; como acontece o domínio dos instrumentos e das técnicas; como se dá o aprendizado das múltiplas linguagens e símbolos; como em cada tempo se aprende o exercício da liberdade e racionalidade, da criatividade e sensibilidade, da memória e identidade, etc. Partir das contribuições das ciências na compreensão desses complexos processos de formação, que vão se dando em cada tempo da vida, será um ponto de partida orientador do que escolher, estruturar e do que ensinar, aprender, formar (ARROYO, 2007, p. 46).
\end{abstract}

Nesse sentido, pensamos o currículo como uma 'bússola', um guia que orienta o caminho pedagógico, ou seja, indica o destino que se pretende atingir diante do compromisso político e pedagógico assumido no projeto de educação escolar (LEAL, 2005). Assim, defendemos que o currículo é um elemento pedagógico sempre em construção (SILVA, 2011).

Moreira e Candau (2003) compreendem o currículo como aquele que se faz por uma relação estreita com as práticas educativas e que é a partir dele que as funções básicas da escola se realizam.

Conforme Arroyo (2007), as propostas curriculares nas escolas vêm sendo cristalizadas pela visão dos professores sobre o ato educativo e o conhecimento, no entanto, o autor alerta que o currículo precisa sempre ser revisitado, revisto e reinterpretado, para representar os anseios da comunidade escolar e transmitir uma identidade que está e vai sendo construída.

Dessa maneira, Arroyo (2013) afirma que o currículo é um território de disputa e necessita sempre estar aberto às novas preocupações sociais, históricas e culturais emergentes no tempo. Essa prevenção do autor também está relacionada à perspectiva de que "[...] vêm crescendo as sensibilidades para com o currículo das escolas, porque percebemos que a organização curricular afeta a organização de nosso trabalho e do trabalho dos educandos" (ARROYO, 2007, p. 18).

Conceber o currículo, portanto, significa construir ideias educativas que têm por compromisso pedagógico a formação dos alunos. Somado a isso, a Lei de Diretrizes e Bases da Educação - LDBEN (BRASIL, 1996), em seu Art. 23, sugere uma organização diversificada das escolas em séries, ciclos, etc., tendo como critério os processos de formação e aprendizagem dos educandos. Dessa maneira, percebemos que a indicação pressupõe formas de organização escolar que implicam em diferentes maneiras de organização do próprio currículo. 
DOI: https://doi.org/10.33238/ReBECEM.2021.v.5.n.1.25246

O plano de trabalho docente, nesse contexto, pode ser entendido como o currículo em ação. Nele estará a expressão singular e de autoria de cada professor acerca da concepção curricular construída nas discussões coletivas.

A partir disso, cabe a discussão sobre a autonomia das instituições escolares em organizarem suas práticas pedagógicas com base nos parâmetros gerais estabelecidos pelo Conselho Nacional de Educação (CNE), como as diretrizes pedagógicas de cada nível, etapa e modalidade da Educação brasileira. Acrescentamos, assim, que as escolas podem e devem analisar as propostas com base em seu contexto e têm o direito de prever especificidades próprias em suas propostas pedagógicas (BRASIL, 1996).

Consequentemente, diante do conceito e das possibilidades de organização curricular na Educação Básica, as diretrizes nacionais (BRASIL, 2010) esclarecem que:

\begin{abstract}
Art. 11. A escola de Educação Básica é o espaço em que se ressignifica e se recria a cultura herdada, reconstruindo-se as identidades culturais, em que se aprende a valorizar as raízes próprias das diferentes regiões do País.

Parágrafo único. Essa concepção de escola exige a superação do rito escolar, desde a construção do currículo até os critérios que orientam a organização do trabalho escolar em sua multidimensionalidade, privilegia trocas, acolhimento e aconchego, para garantir o bem-estar de crianças, adolescentes, jovens e adultos, no relacionamento entre todas as pessoas (BRASIL, 2010).
\end{abstract}

Pensamos, desse modo, que é nessa direção que surge a proposta de um currículo aberto. Ele é concebido a partir da participação ativa de todos, que captam o novo, o socialmente relevante, e que pode complementar conhecimentos já organizados dando mais sentido aos conteúdos escolares, aproximando os contextos interno e externo das escolas. A partir disso, as diretrizes evidenciam para as formas de organização curricular que as instituições de ensino de Educação Básica considerem:

\footnotetext{
Art. 13: $\S 3^{\circ}$ A organização do percurso formativo, aberto e contextualizado, deve ser construída em função das peculiaridades do meio e das características, interesses e necessidades dos estudantes, incluindo não só os componentes curriculares centrais obrigatórios, previstos na legislação e nas normas educacionais, mas outros, também, de modo flexível e variável [...] (BRASIL, 2010, grifo nosso).
}

Isso significa que, praticar uma proposta curricular implica em analisar as possibilidades que emergem do próprio contexto em que ele será evidenciado em práticas pedagógicas que, no que lhe concerne, traduzem intenções em ações educativas coerentes com a formação plena dos alunos. Assim, corroboramos com Arroyo (2007) quanto à seguinte reflexão:

À medida que passamos a entender mais desses processos de aprender, os currículos, o que ensinar e como adquirem novas dimensões. A questão nuclear 
DOI: https://doi.org/10.33238/ReBECEM.2021.v.5.n.1.25246

não deixa de ser o que ensinar, como ensinar, como organizar os conhecimentos, porém tendo como parâmetro os processos de aprendizagem dos educandos em cada tempo humano, tempo mental, cultural. As lógicas do aprender humano passam a ser as determinantes do ordenamento dos conteúdos do ensinar. Somos obrigados a repensar e superar as tradicionais lógicas centradas em uma suposta ordem precedente, hierarquizada e segmentada dos conhecimentos e somos obrigados a perguntar-nos pela lógica em que toda mente humana aprende. Um olhar mais profissional da docência e do ordenamento curricular (ARROYO, 2007, p. 35).

Consequentemente, possibilitar aos professores e às escolas (re)construir continuamente seus programas curriculares consistem em uma atividade que precisa ponderar sobre o papel do conhecimento científico (antigo e novo) na formação dos alunos, mais que impor ou cristalizar conteúdos. Nesse processo,

\begin{abstract}
Repensar os currículos pode significar priorizar essas ciências, tirá-las do lugar secundarizado e moralizante para um lugar de destaque na compreensão crítica dos valores, das culturas, do processo civilizatório e de formação como humanos. Repensar os currículos na ótica da formação plena dos educandos pode significar, também, uma releitura das ciências que tanto lugar e tão destacado têm nas hierarquias curriculares. Preocupadas com a formação plena dos educandos, as ciências adquirem novas dimensões e outras prioridades (ARROYO, 2007, p. 44).
\end{abstract}

A partir disso, os sistemas de ensino e as escolas precisam reorganizar o sentido atribuído aos tempos, aos espaços, ao trabalho e aos currículos na lógica do respeito às especificidades formativas de cada período da vida. Em outras palavras, os profissionais da Educação necessitam promover “[...] formas diversificadas de organização escolar que interrogam as lógicas em que os conteúdos da docência têm sido selecionados, organizados e transmitidos" (ARROYO, 2007, p. 45).

Assim, “[...] o plano de trabalho docente é, portanto, o currículo em ação. Nele estará a expressão singular e de autoria, de cada professor, da concepção curricular construída nas discussões coletivas" (PARANÁ, 2008. p. 73, grifo do documento). Portanto, contemplar a inclusão das temáticas recentes faz parte do trabalho docente em função do contexto histórico em que vivemos, pois:

O plano é o lugar da criação pedagógica do professor, onde os conteúdos específicos receberão abordagens contextualizadas histórica, social e politicamente, de modo que façam sentido para os alunos nas diversas realidades regionais, culturais e econômicas, contribuindo com sua formação cidadã (PARANÁ, 2008, p. 73).

Todos esses pressupostos estão diretamente relacionados, neste artigo, aos conteúdos de Ciências Naturais elencados nos currículos escolares da Educação Básica. Atualmente, é reconhecido o potencial do cotidiano como ponto de partida para 


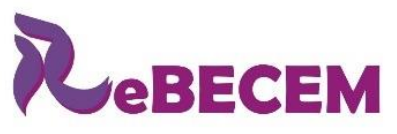

Revista Brasileira de Educação em

Ciências e Educação Matemática

DOI: https://doi.org/10.33238/ReBECEM.2021.v.5.n.1.25246

problematizar os conhecimentos constituídos nas Ciências e a partir dele ensinar os conteúdos em sala de aula, tomando como pressuposto a percepção do meio em que se vive e como ele se desenvolve (BRASIL, 2010).

Nossa compreensão é a de que os conhecimentos curriculares precisam ser contextualizados e apresentados de maneira crítica aos alunos, o que também favorece a possibilidade de pensar um currículo aberto e articulado com novos dados, novas informações que vão surgindo no bojo das Ciências de referência (Física, Química e Biologia).

O currículo de Ciências não pode ser um documento fechado que não admita alterações, adaptações, adequações para receber novas preocupações com o ensino de conteúdos que estão emergindo nesta área. Por isso, é importante evidenciar que o currículo tem relação direta com o saber fazer do professor, que sua abordagem na formação inicial é indispensável e os debates sobre seus limites não podem passar despercebidos desse processo, pois, como visto, ele atua como eixo estruturante do planejamento e da ação docente cotidianos.

A seguir, apresentamos os encaminhamentos metodológicos adotados na pesquisa, abrangendo os processos de coleta e análise dos dados, resultando na evidenciação de uma categoria e três subcategorias analíticas, mediante a análise dos registros dos participantes da pesquisa.

\section{Encaminhamentos metodológicos}

A pesquisa, cujos resultados aqui trazemos, foi desenvolvida na perspectiva qualitativa, segundo aportes de Bogdan e Biklen (1994). Essa abordagem de pesquisa é largamente utilizada no campo das Ciências Humanas e Sociais, dando suporte aos pesquisadores no estudo de temáticas não estritamente quantificáveis e que demandam uma descrição detalhada de diferentes aspectos do fenômeno ou objeto sob investigação.

$\mathrm{Na}$ abordagem qualitativa os dados coletados são pormenorizados em descrições variadas e interpretados em sua complexidade de relações. Segundo Bogdan e Biklen (1994) "o objetivo dos investigadores qualitativos é o de melhor compreender o comportamento e experiência humanos. Tentam compreender o processo mediante o qual as pessoas constroem significados e descrever em que consistem estes mesmos significados" (p. 70). 


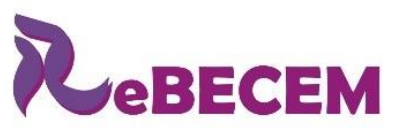

\section{Revista Brasileira de Educação em \\ Ciências e Educação Matemática}

DOI: https://doi.org/10.33238/ReBECEM.2021.v.5.n.1.25246

Quanto aos objetivos, a pesquisa apresentou caráter exploratório, de acordo com Gil (2008), favorecendo uma maior familiaridade com o objeto investigado, a saber, as noções de licenciandos de Ciências Biológicas e Pedagogia sobre a contextualização do currículo. Em relação aos aos procedimentos técnicos, foi empreendida uma investigação bibliográfica em livros e artigos científicos relacionados ao estudo do currículo, dos saberes curriculares, da formação inicial de professores e as novidades científicas no campo das Ciências Naturais.

O problema da pesquisa anteriormente apresentado suscitou a necessidade de melhoria da formação inicial de licenciandos em Ciências Biológicas e Pedagogia de uma Universidade Pública do Estado do Paraná, onde atuamos como professores formadores, a partir de um curso formativo, proporcionando a eles noções claras sobre as possibilidades de contextualização do currículo escolar frente às constantes novidades científicas das Ciências Naturais, muitas delas geradoras de grande impacto nos canais midiáticos e na vida cotidiana dos alunos.

A intervenção foi realizada, por convite, com 26 (vinte e seis) participantes, sendo: 14 (catorze) estudantes do quarto ano de Pedagogia; 9 (nove) do quarto ano e 3 (três) do quinto ano de Ciências Biológicas. A faixa etária (média) dos participantes foi de 23 (vinte e três) anos. Apenas um dos cursistas (de Ciências Biológicas) já possuía outra graduação, por coincidência, em Pedagogia. Quanto à experiência docente prévia, 3 (três) participantes de Ciências Biológicas possuíam 5 (cinco) anos de docência e 11 (onze) de Pedagogia possuíam, aproximadamente, 2,5 anos (dois anos e meio).

A estrutura do curso, apresentada no Quadro 1, descreve os módulos, divididos em momentos formativos (observe a coluna 1), e as atividades propostas aos cursistas (observe a coluna 2), somaram um total de 40 (quarenta) horas.

\begin{tabular}{|c|c|}
\hline $\begin{array}{l}\text { Módulo I } \\
\text { Momento } 1 \text { - Acolhida e diagnose } \\
\text { Momento } 2 \text { - Explicitação da estrutura geral } \\
\text { do curso } \\
\text { Momento } 3 \text { - Introdução e reflexão inicial } \\
\text { Momento } 4 \text { - Instruções para atividade }\end{array}$ & $\begin{array}{l}\text { No Módulo I os pesquisadores evidenciaram algumas } \\
\text { noções prévias dos estudantes quanto à temática do } \\
\text { curso e propuseram estudos de textos sobre currículo, } \\
\text { ensino e contextos sociais recentes, além de abertura } \\
\text { dos programas curriculares para conhecimentos } \\
\text { científicos recentes. }\end{array}$ \\
\hline $\begin{array}{l}\text { Módulo II } \\
\text { Momento } 1 \text { - Introdução e reflexão inicial } \\
\text { Momento } 2 \text { - Aula expositiva dialogada } \\
\text { Momento } 3 \text { - Discussão e reflexão } \\
\text { Momento } 4 \text { - Instruções para atividade }\end{array}$ & $\begin{array}{l}\text { No Módulo II foi proposta uma discussão sobre } \\
\text { 'diferentes conceitos de currículo'. A partir de aula } \\
\text { expositiva e dialogada, apresentamos os documentos } \\
\text { nacionais e estaduais a respeito do currículo e } \\
\text { sugerimos discussão e reflexão sobre os novos } \\
\text { conhecimentos no ensino de ciências naturais, com } \\
\text { foco na abertura do currículo para tal proposta. }\end{array}$ \\
\hline
\end{tabular}


DOI: https://doi.org/10.33238/ReBECEM.2021.v.5.n.1.25246

\begin{tabular}{|c|c|}
\hline Atividade extraclasse & $\begin{array}{l}\text { O Módulo III consistiu na realização de entrevistas } \\
\text { com professores que lecionam Ciências no Ensino } \\
\text { Fundamental, a fim de identificar as percepções } \\
\text { quanto à temática do curso. }\end{array}$ \\
\hline $\begin{array}{l}\text { Módulo IV } \\
\text { Momento } 1 \text { - Atividade inicial } \\
\text { Momento } 2 \text { - Reflexão sobre os dados } \\
\text { coletados } \\
\text { Momento } 3 \text { - Instruções para atividade } \\
\text { extraclasse }\end{array}$ & $\begin{array}{l}\text { No Módulo IV foi realizada a transcrição e análise das } \\
\text { entrevistas realizadas pelos cursistas, sob a orientação } \\
\text { dos pesquisadores, a partir do referencial da Análise } \\
\text { Textual Discursiva (ATD). Em seguida, a socialização } \\
\text { dos resultados. Para o próximo módulo foi solicitada } \\
\text { leitura prévia de textos referentes ao currículo. }\end{array}$ \\
\hline $\begin{array}{l}\text { Módulo V } \\
\text { Momento } 1 \text { - Introdução e diagnose } \\
\text { Momento } 2 \text { - Atividade em grupo (Pedagogia) } \\
\text { Momento } 3 \text { - Atividade em grupo (Ciências } \\
\text { Biológicas) } \\
\text { Momento } 4 \text { - Instruções para atividade do } \\
\text { módulo VI }\end{array}$ & $\begin{array}{l}\text { No Módulo V as propostas de leitura e discussão do } \\
\text { texto empregaram as estratégias de Ensino- } \\
\text {-Aprendizagem indicadas por Bordenave e Pereira } \\
\text { (1991), que consistem, além de se aprofundar num } \\
\text { tema de discussão específico, em estabelecer } \\
\text { estratégias de estudo para uma discussão e reflexão } \\
\text { apresentadas nos textos, bem como participação em } \\
\text { grupo. Em seguida, em grupos, os participantes } \\
\text { realizaram atividades referentes ao próximo módulo. }\end{array}$ \\
\hline $\begin{array}{l}\text { Módulo VI } \\
\text { Momento } 1 \text { - Aula expositivo-dialogada } \\
\text { (temas geradores) }^{5} \\
\text { Momento } 2 \text { - O trabalho docente com Tema } \\
\text { Gerador } \\
\text { Momento } 3 \text { - Atividade em grupo } \\
\text { Momento } 4 \text { - Atividade extraclasse }\end{array}$ & $\begin{array}{l}\text { No Módulo VI os pesquisadores apresentaram os } \\
\text { temas geradores como uma possibilidade de organizar } \\
\text { o ensino de conteúdos de ciências naturais, discutindo } \\
\text { um exemplo de plano de ensino que utiliza o tema } \\
\text { gerador para a organização da prática docente. } \\
\text { Indicaram uma atividade em grupo a partir dos temas } \\
\text { geradores. Na atividade extraclasse foi solicitado aos } \\
\text { cursistas para darem continuidade aos planos de } \\
\text { ensino iniciados em sala, enviando as dúvidas para os } \\
\text { pesquisadores para esclarecimentos. }\end{array}$ \\
\hline $\begin{array}{l}\text { Módulo VII } \\
\text { Atividade extraclas }\end{array}$ & $\begin{array}{l}\text { No Módulo VII foi proposta a continuidade e } \\
\text { organização da atividade de ensino a partir de temas } \\
\text { geradores em ciências naturais (plano de ensino). }\end{array}$ \\
\hline $\begin{array}{l}\text { Módulo VIII } \\
\text { Encontro Final } \\
\text { Momento } 1 \text { - Estratégica Pedagógica } \\
\text { Momento } 2 \text { - Encerramento }\end{array}$ & $\begin{array}{l}\text { No Módulo VIII foi proposta a apresentação dos } \\
\text { planos de ensino elaborados pelas equipes abordando } \\
\text { conhecimentos recentes das ciências naturais a partir } \\
\text { de temas geradores, em articulação com os programas } \\
\text { curriculares. Por fim, realizou-se uma avaliação do } \\
\text { curso de extensão. }\end{array}$ \\
\hline
\end{tabular}

Quadro 1 - Estrutura geral do curso ${ }^{6}$

Fonte: dos autores.

Os módulos do curso foram sistematizados a partir de uma sequência ordenada de aprofundamento dos assuntos abordados, em relação às etapas predecessoras, e observação do acompanhamento dos cursistas. Por um cuidado ético, o anonimato dos

\footnotetext{
${ }^{5}$ Como uma opção, apresentamos a proposta de ensino a partir de Temas Geradores, inicialmente delineada por Freire (1981). Essa abordagem metodológica leva em consideração o contexto em que os alunos estão inseridos. Lembramos que Freire (1981) a desenvolveu pensando na alfabetização de Jovens e Adultos, em que o contexto dos alunos era o ponto de partida para elencar os temas que seriam estudados e assim promover a alfabetização. Foi a partir dos pressupostos dos temas geradores, com base em Freire (1981), que Delizoicov; Angotti e Pernambuco (2000) fizeram a transposição desses conhecimentos para o ensino de Ciências.
}

${ }^{6}$ Os conteúdos trabalhados no curso podem ser obtidos por meio de contato com os pesquisadores, pelo $e$ mail: fratonidri@hotmail.com. 
DOI: https://doi.org/10.33238/ReBECEM.2021.v.5.n.1.25246

participantes foi proposto a partir das seguintes codificações: LP1 a LP14, para menção aos licenciandos do curso de Pedagogia; LB1 a LB12, para menção aos licenciandos de Ciências Biológicas.

Durante a intervenção (curso), foram várias as atividades realizadas pelos participantes. Uma delas, ao final do curso, compreendeu dar resposta a um questionário composto por diversas questões relativas ao curso e às noções dos licenciandos sobre os assuntos abordados. Duas das questões do questionário foram consideradas para os resultados que trazemos neste artigo: I. Em sua opinião, o currículo norteador de sua formação profissional (inicial) é sensível aos conhecimentos recentemente desenvolvidos e socializados pelas Ciências Naturais (Física, Química, Biologia)? Justifique sua resposta; II. Em sua opinião, o que representa a formação de professores para “A inclusão de temas científicos recentes no âmbito do Ensino de Ciências"?

As respostas dos licenciandos a essas questões foram organizadas e interpretadas a partir dos encaminhamentos teórico-metodológicos da Análise Textual Discursiva (ATD), com base em Moraes e Galiazzi (2007). A ATD é uma metodologia empregada para análise de dados em pesquisas qualitativas cujo objetivo proporcionar novas compreensões sobre os fenômenos e discursos investigados.

De acordo com Moraes (2003), a ATD corresponde a um procedimento interpretativo resultante de algumas etapas principais: (i) a unitarização, (ii) a categorização, (iii) o captar do emergente e o (iv) processo de auto-organização (MORAES, 2003).

A unitarização (ou desmontagem dos textos) é a fase em que o material qualitativo a ser analisado passa por um exame detalhado, sofrendo fragmentações que objetivam gerar unidades constituintes, enunciados que mantenham relação com o fenômeno/objeto estudado.

Já a categorização (ou estabelecimento de relações) corresponde à etapa de análise das relações possíveis entre os fragmentos unitarizados, combinando-os e classificandoos no sentido de se chegar a agrupamentos por afinidade semântica.

O captar do novo emergente consiste nova interpretação (dos dados) que se apresenta possível a partir das etapas anteriores da ATD. Essa nova interpretação é comunicada na forma de um metatexto.

Todo o percurso analítico da ATD é auto-organizado e apresentado como um processo racionalizado e planejado. A partir dele novas compreensões dos dados podem surgir. Ainda assim, é importante considerar o fator "imprevisibilidade" no resultado 
DOI: https://doi.org/10.33238/ReBECEM.2021.v.5.n.1.25246

interpretativo, pois as combinações dos fragmentos e categorias suportam esse tipo de movimento. Apresentamos, a seguir, a análise de dados realizada.

\section{Resultados e Discussões}

Com a transcrição das respostas, constituindo o $\operatorname{corpus}^{7}$ analítico, prosseguimos com as etapas de unitarização dos textos gerando fragmentos textuais. Após repetidas leituras desses fragmentos foi possível realizar agrupamentos dos excertos, por afinidade de sentido, configurando uma categoria analítica intitulada "Formação Docente", apresentada no Quadro 2, com suas respectivas subcategorias: I. Insuficiências da formação inicial; II. Contribuições do curso para a formação inicial; III. Limitações do curso para a formação inicial.

Nesta categoria foram apresentados fragmentos textuais que relatavam a respeito do processo formativo dos professores, seus pontos positivos, negativos, insuficiências e sugestões. Nesse sentido, compreendemos que a formação docente é aquela que apresenta um conjunto de saberes para a profissionalização da docência. Os autores Tardif (2012), Mello (2000), Pimenta (1999) e Polon (2012) constituem nosso referencial teórico para evidenciar os conhecimentos formativos que poderiam ser abordados durante a formação inicial para oferecer subsídios aos licenciados, de modo que os mesmos possam desenvolver uma prática pedagógica coerente e contextualizada.

A seguir, inserimos exemplos dos excertos transcritos e analisados de modo a corroborar com a categorização empreendida - Formação Docente. Os exemplos, representativos como são, limitam-se no texto em função da quantidade de dados coletados. Na primeira coluna do Quadro 2 organizamos as subcategorias e na segunda coluna os registros selecionados.

\begin{tabular}{|c|l|}
\hline Subcategorias & \multicolumn{1}{|c|}{ Exemplos de respostas dos cursistas } \\
\hline & $\begin{array}{l}\text { Não, pois em nosso caso do curso de Pedagogia temos apenas disciplinas de } \\
\text { metodologia, isto é, voltadas para o "ensino de” Matemática, Língua } \\
\text { Portuguesa, especificamente Ciências, entre outros. Dessa forma, devido ao seu } \\
\text { pouco tempo disponibilizado por essas metodologias, não contribui } \\
\text { significativamente ao ensino desses conhecimentos emergentes (LP1). } \\
\text { formação inicial }\end{array}$ \\
& $\begin{array}{l}\text { Pode ser sensível dependendo do professor, caso ele queira inserir temáticas } \\
\text { recentes ou não (LB1). }\end{array}$ \\
\hline
\end{tabular}

\footnotetext{
7 [...] o conjunto dos documentos tidos em conta para serem submetidos aos procedimentos analíticos
} (BARDIN, 2011, p. 126). 
DOI: https://doi.org/10.33238/ReBECEM.2021.v.5.n.1.25246

\begin{tabular}{|c|c|}
\hline & $\begin{array}{l}\text { Não, pois o sistema é falho e carece de materiais atualizados, embora os meios } \\
\text { de pesquisa sejam acessíveis a todos, pode ser que o professor não atualize este } \\
\text { recurso (LB2). } \\
\text { Tendo em vista que iniciamos a única disciplina em torno das Ciências neste } \\
\text { último ano e por enquanto não dá para negar ou afirmar. Principalmente a } \\
\text { Biologia que não é uma Ciência exata (LP1). } \\
\text { As disciplinas deixam a desejar (LP2). }\end{array}$ \\
\hline $\begin{array}{l}\text { Contribuições do } \\
\text { curso para a } \\
\text { formação inicial }\end{array}$ & $\begin{array}{l}\text { Eu não tenho realmente a experiência e vivência como docente, apenas estágio, } \\
\text { e eu acho que entrando numa sala de aula, não pensaria nessa importância de se } \\
\text { trabalhar esses conteúdos científicos mais recentes, que emergem do interesse do } \\
\text { aluno. Com o curso foi possível me levar a refletir sobre a importância deles que } \\
\text { muitas vezes não estão inseridos no livro didático, mas que também são de suma } \\
\text { importância, é o que está na realidade do dia a dia dos alunos, que é o que acaba } \\
\text { sendo de interesse deles. Então acredito que me serviu de grande importância } \\
\text { sim (LP1). } \\
\text { Até a presente data esse assunto era desconhecido para mim. O que irá contribuir } \\
\text { com a minha futura formação dentro da sala de aula (LB2). } \\
\text { [O curso foi] enriquecedor para minha formação, pois me levou a refletir a } \\
\text { prática. Contribuiu bastante, eu gostei muito de ter feito o curso, até porque eu } \\
\text { não tinha essa noção que o currículo é sim flexível, posso sim mexer nesses } \\
\text { conteúdos do currículo e fazer a inserção que vai depender de mim. Os temas } \\
\text { geradores era algo que eu até então não conhecia, não saberia falar se alguém } \\
\text { me perguntasse sobre e a partir do curso eu passei a ter essa consciência sobre } \\
\text { os temas geradores e também a respeito da inserção de temáticas recentes e } \\
\text { quanto isso é importante na educação. Sim, me ensinou como posso trabalhar } \\
\text { essas temáticas recentes, foi um ensino breve, mas que esclareceu muitas dúvidas, } \\
\text { pois na minha opinião o professor está precisando ser mais dinâmico na sala de } \\
\text { aula, atrair mais os alunos. O curso evidenciou como abordar temáticas recentes, } \\
\text { a importância de tal e também necessidade, a integração dos cursos, a dinâmica } \\
\text { das aulas e entrevista com professor (LP1). } \\
\text { o curso de Pedagogia tem a disciplina Metodologia, mas aqui consegui ver um } \\
\text { pouco da prática e me ajudar nas aulas de Ciências que tenho. Me ajudou e me } \\
\text { mostrou como é importante um professor ser atualizado (LP2). }\end{array}$ \\
\hline $\begin{array}{l}\text { Limitações do } \\
\text { curso para a } \\
\text { formação inicial }\end{array}$ & $\begin{array}{l}\text { Não houve limitações. Apenas dificuldades para fazer mapa conceitual (LP1). } \\
\text { Não houve apontamentos nesse aspecto pela cursista (LP2). } \\
\text { A evidência da falta de metodologia em Biologia e a de conteúdo em Pedagogia } \\
\text { (LB1). } \\
\text { Não houve apontamentos nesse aspecto pela cursista (LB2). }\end{array}$ \\
\hline
\end{tabular}

Quadro 2 - Organização dos dados em categoria analítica

Fonte: dos autores.

No que diz respeito às percepções dos licenciandos para a primeira subcategoria que abordaram as Insuficiências da formação inicial, explicitamos as manifestações de cinco deles: LP1, LB1, LB2, LP1, LP2. As estudantes de Pedagogia apontaram que na graduação as disciplinas não contemplavam os conteúdos emergentes e a carga horária das disciplinas de metodologia não favorecia o trabalho pedagógico de temáticas recentes. 


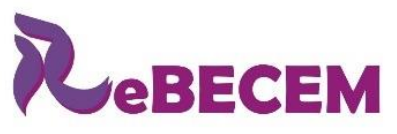

Revista Brasileira de Educação em

Ciências e Educação Matemática

DOI: https://doi.org/10.33238/ReBECEM.2021.v.5.n.1.25246

Já no caso dos licenciandos em Biologia, eles enfatizaram que as temáticas só eram inseridas de acordo com o professor da disciplina e indicavam as dificuldades de materiais desatualizados e meios de pesquisa que precisavam ser acessados pelo docente para atualização dos conteúdos a serem trabalhados com os alunos.

Fica evidente, nos excertos analisados, o descompasso entre a formação docente inicial dos participantes e as demandas reais e atuais da sala de aula. O currículo não é apresentado em interlocução com a vida cotidiana dos alunos, acentuando o seguimento de um programa aparentemente rígido e estanque, diverso daquilo que os aprendizes experimentam em suas vidas.

Percebemos, assim, a falta de compreensão dos participantes da pesquisa no que diz respeito aos saberes curriculares que, segundo Tardif (2012, p. 38) “[...] correspondem aos discursos, conteúdos e métodos a partir dos quais a instituição escolar categoriza e apresenta os saberes sociais por ela definidos e selecionados" (grifo nosso). Em outras palavras, é esperado que futuros professores sejam bem preparados para trabalhar com conteúdos curriculares, tendo a compreensão de que eles são, originalmente, saberes social e historicamente construídos e que se relacionarão com alunos de outros momentos histórico-sociais.

Deixar de aproximar os conteúdos curriculares da realidade dos alunos significa, então, perder a oportunidade de relacionar conhecimento humano já produzido com demandas sociais recentes, ampliando o sentido da abordagem do conteúdo e das aprendizagens esperadas.

A sensibilidade para promover essa relação, como destacado por LB1, depende do professor, pois como se percebe essa possibilidade não é abordada na formação inicial em profundidade, ao menos com o grupo de participantes envolvidos na pesquisa. Eles, no entanto, percebem essa deficiência formativa, como nas indicações de LB2 e LP2.

Convém lembrar que em ambas as diretrizes dos cursos de Ciências Biológicas e de Pedagogia (BRASIL, 2001; BRASIL, 2002; BRASIL, 2006) há abertura para inserir novas temáticas na formação dos docentes a partir das demandas emergentes. Portanto, acreditamos que as exigências das novas diretrizes da formação docente (BRASIL, 2019) impliquem em alterações nos projetos pedagógicos dos cursos e em suas propostas curriculares, orientando os professores a agregarem demandas educacionais recentes na formação inicial.

Tendo em vista as insuficiências indicadas, identificamos quatro excertos que contemplaram as Contribuições do curso para a formação inicial (LP1, LB2, LP1, LP2). 


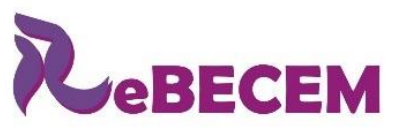

Revista Brasileira de Educação em

Ciências e Educação Matemática

DOI: https://doi.org/10.33238/ReBECEM.2021.v.5.n.1.25246

Destacamos que os licenciandos mencionaram o reconhecimento da importância de se trabalhar os conteúdos contemporâneos, tendo em foco a realidade dos alunos, a reflexão sobre a futura prática docente a partir da inclusão de temáticas recentes e a possibilidade metodológica de inserir temas que possam desencadear as discussões em sala de aula. Somado a isso, os estudantes, também relataram sobre a questão da atualização dos conhecimentos científicos e como parte da prática pedagógica do professor em contextualizar suas aulas de Ciências na Educação Básica.

A relevância da proposta interventiva pôde ser mensurada a partir do excerto de LP1. Segundo ele, em função de sua inexperiência profissional, foi durante o curso que percebeu a importância de relacionar o dia a dia dos alunos com os conteúdos curriculares, incluindo que muitas informações científicas interessantes e importantes não estão nos livros didáticos, mas podem alcançadas segundo o interesse dos aprendizes.

LP1 reconheceu não ter uma compreensão anterior (antes do curso) sobre a importância da flexibilidade curricular, sobre a responsabilidade do professor em fazer do currículo um ponto de partida para a compreensão do mundo, por parte do aprendiz. Do mesmo modo, LB2 relatou que toda essa discussão era desconhecida por ele e que a partir do curso teve consciência da importância da inserção de temáticas recentes, nas aulas e o quanto isso pode favorecer a educação escolar.

Essa situação relacionada à licenciatura, de não discutir com qualidade as possibilidades do currículo, são preocupantes. Segundo Polon (2012), a abordagem dos conteúdos dos professores que ensinam Ciências é decorrente, principalmente, do processo de formação (inicial). Esse entendimento perpassa pelo reconhecimento de que é na preparação profissional que precisam ser tradados problemas de ensino e de aprendizagem como parte da atividade pedagógica formativa.

Segundo Pimenta (1999), é necessário que na atividade docente o professor valha de seus valores, representações e de tudo a respeito do seu cotidiano. Em suas palavras é preciso “[...] reinventar os saberes pedagógicos a partir da prática social da educação" (p. 25), ou seja, a partir da prática do ensino. Polon (2012) acrescenta que o modo com que o professor seleciona, organiza e problematiza os conteúdos contribui para a formação crítica dos alunos. Assim, entendemos como Souza e Chapani (2015) que:

Tratar do ensino de ciências nos anos iniciais de escolaridade requer, necessariamente, uma reflexão sobre as novas estruturas e exigências da sociedade contemporânea, na qual conhecimentos científicos básicos são fundamentais para que os sujeitos possam participar ativamente da vida em sociedade (p. 121). 
DOI: https://doi.org/10.33238/ReBECEM.2021.v.5.n.1.25246

Por conseguinte, acreditamos que esse investimento na formação inicial dos pesquisados possibilitou a reflexão de situações que serão enfrentadas em seu ambiente de trabalho. Conforme Seixas, Calabró e Sousa (2017), a formação acadêmica assume um processo de construção de conhecimentos que serão carregados pelos professores e, constantemente, aprimorados. Portanto, entendemos que os conteúdos apreendidos pelos cursistas farão parte de um repertório de saberes que poderão ser mobiliados em sua atividade profissional.

Com base em Polon (2012), compreendemos que a mudança na prática pedagógica decorre da formação - seja inicial e/ou continuada, e assim, por meio desse curso, pôde ser desencadeado o reconhecimento da necessidade de contextualização curricular para inserção das temáticas recentes nas aulas de Ciências na Educação Básica.

Mello (2000), igualmente reconhece a necessidade de integração entre teoria e prática desde o início dos cursos de licenciatura. Segundo ele "Essa integração deve ser trabalhada como contextualização dos conhecimentos no mundo social e natural de modo a propiciar situações de aprendizagem significativa aos futuros professores, tanto nas áreas de conteúdo específico como nas áreas de fundamentos educacionais” (p. 106).

Por fim, trouxemos, no Quadro 2, quatro excertos que argumentamos a respeito das Limitações do curso para a formação inicial. Na percepção de três cursistas não houve limitação, indicando apenas certa dificuldade na construção do mapa conceitual utilizado como uma das atividades desenvolvidas no curso.

Para LB1, ficou evidente que em ambos os cursos de graduação existem insuficiências que se correlacionavam. De um lado, no curso de Pedagogia era trabalhada metodologia de Ciências, mas não enfatizava os conteúdos desta área. Por outro, no caso de Biologia focava-se nos conteúdos e não nos conhecimentos didáticos e pedagógicos relacionados ao ensino dos conteúdos. De tal modo, a indicação do licenciando de Biologia mostrou-se como um alerta aos cursos supracitados para repensarem suas propostas curriculares de formação docente, visando suprir essas insuficiências para o desenvolvimento profissional daqueles que ensinarão Ciências na Educação Básica.

Partindo dessas indicações, percebemos que a proposta de formação atendeu às expectativas dos participantes e favoreceu qualitativamente seu desenvolvimento profissional inicial. Conforme indicam Carvalho e Gil-Peréz (2011), adquirir novos conhecimentos prepara os futuros docentes no domínio de conhecimentos científicos que serão base para sua prática pedagógica. Assim, participar do curso promoveu 
DOI: https://doi.org/10.33238/ReBECEM.2021.v.5.n.1.25246

conhecimentos novos no contexto formativo dos cursistas em análise, sobretudo no que diz respeito à percepção da limitação dos currículos das licenciaturas em Ciências Biológicas e Pedagogia (pesquisadas) diante da ênfase ao conteúdo e aos conhecimentos recentes.

\section{Considerações finais}

A partir das interpretações que realizamos das respostas dos cursistas (ressalvando que no artigo expusemos somente exemplos das transcrições), ficou evidenciada a pertinência da proposta formativa, frente ao debate sobre os programas curriculares atuais e os conteúdos científicos produzidos pelas Ciências Naturais de referência (Física, Química e Biologia), no âmbito da educação escolar.

Os dados mostraram a efetividade das discussões no sentido da promoção de uma consciência crítica dos participantes sobre a necessidade de um diálogo contextualizado dos conteúdos curriculares historicamente constituídos com a realidade sócio-histórica em que são trabalhados nas salas de aula. Mais que isso, uma percepção de que essa abordagem não está presente no processo de formação inicial de professores, cabendo aos recém-licenciados o reconhecimento e a adesão dessa perspectiva.

No que se refere à formação docente, analisamos que os cursistas perceberam a carência da formação inicial em contemplar a possível inserção de conteúdos emergentes nas aulas que tratam de conteúdos de Ciências Naturais, de maneira pedagogicamente adequada. Acrescentamos a essa análise a percepção dos estudantes de que o curso de extensão favoreceu sua formação com relação às temáticas recentes nas aulas de Ciências.

Percebemos, ainda, uma visão bastante crítica com relação à formação inicial em que indicam, ao mesmo tempo, a falta de materiais didáticos, tempo para desenvolver as aulas sobre temáticas recentes, ênfase ora para conhecimentos metodológicos de ensino, ora para conteúdos disciplinares atuais. Em adição, evidenciaram que depende também de os formadores inserirem tais conteúdos (pedagógicos e disciplinares) como pauta de inclusão no plano de ensino e, assim, efetivar análises e discussões sobre o trabalho pedagógico a ser realizado na Educação Básica pelos licenciandos.

Por meio do movimento analítico efetivado nesta pesquisa, percebemos o quanto os saberes curriculares apresentaram-se distantes da formação inicial dos cursistas, muitos dos quais se mostraram surpresos com a possibilidade de pensar um currículo 


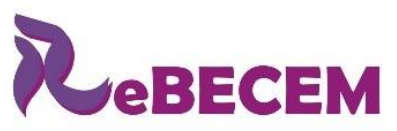

Revista Brasileira de Educação em

Ciências e Educação Matemática

DOI: https://doi.org/10.33238/ReBECEM.2021.v.5.n.1.25246

flexível, aberto e aderente às novidades científicas. Isso sugeriu-nos refletir sobre a importância de componentes formativos que possam contemplar a aprendizagem e a mobilização de saberes curriculares, nos futuros professores, desde a formação inicial.

Finalmente, a intervenção pedagógica possibilitou a sensibilização dos cursistas sobre essa demanda, os quais reconheceram a pertinência e a relevância desse movimento de dinamizar e contextualizar o currículo, sobretudo, no que diz respeito às Ciências Naturais que, diariamente, enriquecem e acumulam a sociedade de novidades científicas, muitas das quais exercem impacto direto e de curto prazo na vida cotidiana de todos os atores escolares, sejam eles professores ou alunos.

\section{Referências}

ARROYO, M. G. Currículo, território em disputa. 5. ed. Petrópolis: Vozes, 2013.

ARROYO, M. G. Educandos e educadores: seus direitos e o currículo. In: BEAUCHAMP, J.; PAGEL, S. D.; NASCIMENTO, A. R. Indagações sobre currículo. Brasília: Ministério da Educação, Secretaria de Educação Básica, 2007, p. 17-52. Disponível em:

http://portal.mec.gov.br/seb/arquivos/pdf/Ensfund/indag2.pdf. Acesso em: 16 maio 2020.

BARDIN, L. Análise de conteúdo. Porto: Edições 70, 2011.

BOGDAN, R. C.; BIKLEN, S. K. Investigação qualitativa em educação. Tradução Maria João Alvarez, Sara Bahia dos Santos e Telmo Mourinho Baptista. Porto: Porto Editora, 1994.

BORDENAVE, J. D.; PEREIRA, A. M. Estratégias de ensino-aprendizagem. 12. ed. Petrópolis: Vozes, 1991.

BRASIL. Lei no 9.394, de 20 de dezembro de 1996. Estabelece as diretrizes e bases da educação nacional. Brasília: Diário Oficial, 1996.

BRASIL. Parecer $\mathbf{n}^{\mathbf{0}}$ 1.301/2001. Diretrizes Curriculares Nacionais para os Cursos de Ciências Biológicas. Brasília: CNE/CES, 2001. Disponível em:

http://portal.mec.gov.br/cne/arquivos/pdf/CES1301.pdf. Acesso em: 16 maio 2020.

BRASIL. Resolução no 7/2002. Diretrizes Curriculares para os cursos de Ciências Biológicas. Brasília: CNE/CES, 2002. Disponível em: http://portal.mec.gov.br/cne/arquivos/pdf/CES072002.pdf. Acesso em: 16 maio 2020. 
DOI: https://doi.org/10.33238/ReBECEM.2021.v.5.n.1.25246

BRASIL. Resolução n⿳ 1/2006. Diretrizes Curriculares Nacionais para o Curso de Graduação em Pedagogia, licenciatura. Brasília: CNE/CES, 2006. Disponível em:

http://portal.mec.gov.br/cne/arquivos/pdf/rcp01_06.pdf. Acesso em: 16 maio 2020.

BRASIL. Resolução no 4/2010. Define Diretrizes Curriculares Nacionais Gerais para a Educação Básica. Brasília: MEC/CNE/CEB, 2010. Disponível em:

http://portal.mec.gov.br/index.php?option=com_docman\&view=download\&alias=15548-d-c-neducacao-basica-nova-pdf\&Itemid=30192. Acesso em: 17 maio 2020.

BRASIL. Resolução CNE/CP no 2/2019. Diretrizes Curriculares Nacionais para a Formação Inicial de Professores para a Educação Básica e institui a Base Nacional Comum para a Formação Inicial de Professores da Educação Básica. Disponível em: http://portal.mec.gov.br/docman/dezembro-2019-pdf/135951-rcp002-19/file. Acesso em: 17 maio 2020.

CARVALHO, A. M. P.; GIL-PERÉZ, D. Formação de professores de Ciências: tendências e inovações. 10. ed. São Paulo: Cortez, 2011.

DELIZOICOV, D.; ANGOTTI, J. A. P.; PERNAMBUCO, M. M. Metodologia do ensino de Ciências. São Paulo: Cortez, 2000.

FREIRE, P. Pedagogia do oprimido. 10. ed. Rio de Janeiro: Paz e Terra, 1981.

GAUTHIER, C.; MARTINEAU, S.; DESBIENS, J. F.; MALO, A.; SIMARD, D. Por uma teoria da pedagogia: pesquisas contemporâneas sobre o saber docente. 3.ed. Ijuí: Unijuí, 2013.

GIL, A. C. Como elaborar projetos de pesquisa. 4. ed. São Paulo: Atlas, 2008.

LEAL, R. B. Planejamento de ensino: peculiaridades significativas. Revista Iberoamericana de Educación, Madri, v. 37, n. 3, p. 1-7, dez, 2005.

MELLO, G. N. Formação inicial de professores para a educação básica: uma (re)visão radical. Revista São Paulo em Perspectiva, São Paulo, v. 14, n. 1, p. 98-110, mar, 2000.

MORAES, R. Uma tempestade de luz: a compreensão possibilitada pela análise textual discursiva. Ciência \& Educação, Bauru, v. 9, n. 2, p. 191-211, out, 2003.

MORAES, R.; GALIAZZI, M. C. Análise Textual Discursiva. Ijuí: Unijuí, 2007.

MOREIRA, A. F. B.; CANDAU, V. M. Educação escolar e cultura(s): construindo caminhos. Revista Brasileira de Educação, Rio de Janeiro, n. 23, p. 156-168, ago, 2003. 
DOI: https://doi.org/10.33238/ReBECEM.2021.v.5.n.1.25246

PARANÁ. Diretrizes Curriculares da Educação Básica: Biologia. Curitiba: SEED, 2008.

Disponível em: http://www.educadores.diaadia.pr.gov.br/arquivos/File/diretrizes/dce_bio.pdf. Acesso em: 16 maio 2020.

PIMENTA, S. G. Formação de professores: identidade e saberes da docência. In: PIMENTA, S. G. (org.). Saberes pedagógicos e atividade docente. São Paulo: Cortez, 1999.

POLON, S. A. M. Teoria e metodologia do ensino de Ciências. Paraná: UNICENTRO, 2012.

SANTOS, A. F. dos. A inserção de temáticas científicas no ensino de Ciências Naturais: uma proposta de formação inicial de professores. 2018. 113 f. Dissertação (Mestrado Profissional em Ensino) - Universidade Estadual do Norte do Paraná, Cornélio Procópio, 2018.

SOUZA, A. L. S.; CHAPANI, D. T. Necessidades formativas dos professores que ensinam Ciências nos anos iniciais. Revista Práxis Educacional, Vitória da Conquista, v. 11, n. 19, p. 119-136, maio/ago., 2015. Disponível em:

http://periodicos.uesb.br/index.php/praxis/article/viewFile/4765/4531. Acesso em: 14 out. 2020.

SEIXAS, R. H. M.; CALABRÓ, L.; SOUSA, D. O. A formação de professores e os desafios de ensinar Ciências. Revista Thema, Porto Alegre, v. 14, n. 1, p. 289-303, fev, 2017.

SILVA, T. T. Documentos de identidade: uma introdução às teorias do currículo. 3.ed. Belo Horizonte: Autêntica, 2011.

TARDIF, M. Saberes docentes e formação profissional. 13. ed. Petrópolis: Vozes, 2012.

Recebido em: 17 de junho de 2020

Aceito em: 05 de abril de 2021 